\title{
Honoring Tribal Spirituality in India: An Exploratory Study of Their Beliefs, Rituals and Healing Practices
}

\author{
Shannal Rowkith and Raisuyah Bhagwan * \\ Community Health Studies Child and Youth Care Programme, Durban University of Technology, Durban, \\ KwaZulu-Natal 4000, South Africa; shannalrowkith254@gmail.com \\ * Correspondence: bhagwanr@dut.ac.za
}

Received: 12 August 2020; Accepted: 9 October 2020; Published: 23 October 2020

\begin{abstract}
This paper presents an exploration of tribal spirituality in India. The study sought to understand the spiritual worldview of tribal communities in India within the context of a community engagement program between a university in India and a tribal community outside Mumbai. The purpose of the engagement was for students and academics to have a deeper understanding of tribal communities, and to formulate community development interventions that could improve their individual and family well-being. A qualitative research approach was utilized to guide the study. The data was collected from two samples, namely, six social work academics and 23 students. Semi structured interviews and focus group discussions were used to collect data from these aforementioned samples following a two-year immersion within this community. The data was analyzed as one dataset using thematic analysis. Three broad themes emerged from the data which focused on the characteristics of tribal communities, tribal spirituality and the healing methodologies used.
\end{abstract}

Keywords: spirituality; tribal; indigenous

\section{Introduction}

Around $7 \%$ of the Indian population follow a separate way of cultural life that differs from the rest of the population of India. This small population has been recognized as tribals (Chatterjee and Sharma 2018). For the purposes of this study, the terms tribals and indigenous will be used interchangeably. India is in fact home to one of the largest tribal populations across the planet (Das and Bose 2015; Ramya et al. 2017; Shrivastava et al. 2013). From the perspective of civilized society, tribal communities are usually categorized as economically disadvantaged and comparatively less socially advanced (Purkayastha 2016; Shrivastava et al. 2013; Marchang 2018; Andrabi 2018). Although the Indian Government since has endeavored to alleviate the socio-economic conditions of tribals, they remain socially, economically, culturally and educationally impoverished due to their uncommon occupational and geographical circumstances (Andrabi 2018; Bhatla 2017). Despite this, the tribal Indian group boasts a richness of indigenous culture, folklore and history (Purshottam and Dhingra 2017).

\section{Background to the Study}

A focus on Dalit and tribal social work (Rao 2016) led the University, and its academics and students, to become involved in a community engagement initiative. The engagement with this particular tribal community has been an enduring one that was forged with one academic, and has sustained itself for more than 15 years. Consequently, the relationship he established with them allowed him, other academics and students of the Department of Social Work to immerse themselves in this space and engage in community development programs through the sharing of academic knowledge and expertise. One consequence of developing a more intimate and trusting relationship 
with the tribal community is that it allowed for a deeper understanding of their spiritual worldview, within the context of developing mutually constructed community development initiatives to improve their physical and emotional well-being.

Tribal social work in India resonates with decolonized social work that endeavors to derive its theories and methods from the history and culture of Indian civilization (Rao 2016). Strong concerns have been voiced in the literature regarding the privileging of western social work and the inadequacy of its methodologies in India (Prasad and Vijayaslakshmi 1997). Hence the call for the indigenization of social work practice, whereby the indigenization of social work is seen to refer to the processes by which traditional and local helping interventions are integrated into mainstream social work. Consequently, social workers in non-western contexts have been urged to move away from merely modifying western social work theory, and towards "generating knowledge and practice models from the ground up, drawing on the beliefs, values, customs and cultural norms of local and indigenous helping practices. It is within this context that the University sought to extend its traditional classroom space into the deep forest space where students could grasp aspects related to marginalization, oppression, community development whilst learning the indigenous ways of knowing of tribal communities. It has been argued that such processes which use local cultures as a primary source for knowledge and practice development, can enable social work to become culturally appropriate, relevant and authentic" (Gray et al. 2010, p. 5). It is within this context that Nimmagadda and Martell (2010) wrote that social work in India originates with the client in the local community. They added that authentic practice must be predicated on local knowledge, and that attempts to generate local solutions for local needs are participatory, working with rather than for clients. These approaches require a more community-oriented approach to intervention, and affirm the links between mind, body and culture. This builds a case for the current paper which sheds light on an area wherein little has been written around tribal culture and spirituality.

Social work's literature on cross-cultural practice exemplifies the effectiveness of interventions based on a social worker practitioner's acquisition of a particular body of cultural knowledge, values and skills (Clark 2000; Weaver 2000). The acquisition of culturally-specific knowledge, values and skills leads to an understanding of other perspectives and cultures, which can be used by social workers to develop a deeper understanding of the client's cultural frame of reference (Clark 2000). The effect of learning within the space of the tribal community was strengthened as community members became teachers. Students encountered the immeasurable generosity and capacity of the tribals to act as collaborators in their learning. The mandate of the department was to initiate a community engagement program that nurtured an understanding of tribal cultural identities, hence the engagement initiative centered on tribal spiritual and cultural values, beliefs and practices, whilst preparing graduates of diverse backgrounds to work not only in mainstream social work settings, but also in tribal and other rural contexts in India. More important was the joint community development programs that emerged through this engagement.

One aspect of the community engagement program was to teach the students community organizing. As such, the engagement initiative provided the students with an opportunity to be immersed within a tribal context, in order to better understand community needs and initiate organization and development initiatives. Thus, through community-based engagement, not only did they have the opportunity to grasp contemporary social issues within a marginalized community, but they could apply the theoretical principles and methodologies of community-based work. One important learning opportunity that emerges through engagement is the acquisition of indigenous knowledge, which has been documented as an offspring of engaged learning (Bhagwan 2017). This notion is supported by other writers who believe that students learn salient cultural customs through community organization (Mizrahi et al. 2016). Moreover, social work students learn social responsibility and respect for diversity, and develop multicultural competence (Bhagwan 2017). Consequently, writers such as Gray (2002) have urged the reconceptualization of social work and stressed the need to rediscover its indigenous roots. 


\section{Community Engagement in Context}

Immersing students in community spaces brings the benefit of exposing them to ideas of inequality, social justice, exclusion, and tradition that are not normally embedded in Indian history (Rao 2016). Social work has in fact been criticized for its failure to consider the sociopolitical and economic context dominated by ethnocentric factors such as caste, tribe, culture, religion and ethnicity, which have an impact on the poor and marginalized sectors of the community. These factors led to the consideration of community-engaged teaching within this context. There is a broad awareness of the need to assist such communities, with one of the key areas being their quality of life, particularly from the academic institutional perspective, within the context of social work and community engagement initiatives. Tieken (2017) and Hall (2010) supported these notions, describing community engagement as the relationship between higher education institutions and their respective communities, which has qualities such as reciprocity, mutual respect, shared authority, and the co-creation of goals and outcomes as its basis. The aim of this paper then is to describe the spiritual beliefs and practices of the tribals in India. A case for this paper lies in the fact that there is little scholarly work that captures the spiritual worldviews of the tribal community in India. Moreover, there is little scholarly work on community engagement initiatives that focuses on tribals (Campbell and Christie 2009; O'Donahoo and Ross 2015). This paper aims to strengthen the scholarly trail regarding the tribal community in India.

\section{Literature Review}

Jakovljevic (2017) defined spirituality as an integrating force that involves the perception of transcendental beliefs and values that provide a sense of deeper meaning and unity between self, people, nature and the universe. It has also been seen as a sense of connectedness to all others, involving intimate bonds to kin, communities, nature and the universe (Walsh 2008 cited in (McGoldrick and Hardy 2019)). Spirituality among tribal communities plays an integral role in their culture, and serves as a beacon for the way in which they live their lives (Chatterjee and Sharma 2018; James 2015; Ritskes 2011). As Kincheloe (2011) argued, "a human being simply can't exist outside the inscription of community with its processes of relationship, differentiation, interaction, and subjectivity" (p. 192). For indigenous peoples, community consists of people in the surrounding vicinity, together with connections with the environment or whole earth, relationships with the ancestors who have gone before, and relationships with those who are to come. Hence "community means the living, the unborn, the dead, and nature as a whole" (Wangoola 2000, p. 271). These three threads are interwoven within the context of spirituality amongst tribals, and allows for a community that is expansive and dynamic (Ritskes 2011). This spiritual relationship is exhibited in numerous ways, which include the practice of taboos, utilizing minimal natural resources while undertaking reverential rituals for these resources, and shifting cultivation (James 2015). Tribal people further believe that a divine or supernatural being has bestowed nature with rich gifts, concurrently fulfilling the role of guide and teacher for their safety and prosperity. Subsequently, the engagement with omens, dreams and divination also comprises a fundamental aspect of tribal spirituality (Kechutzar 2008 cited in (James 2015)).

Many scholars have provided a wider definition of spirituality, as the search for meaning and purpose (Drury 2016; Dombo and Flood 2015; Chaube 2015; Slade 2011; Walsh 2010). Similarly, social work scholars Canda et al. (2010) defined spirituality as referring "to a universal and fundamental human quality involving the search for a sense of meaning, purpose, morality, wellbeing, and profundity in relationships with ourselves, others and ultimate reality, however understood" (p. 59). Another beneficial approach is to distinguish between indigenous spirituality as a more multifaceted phenomenon as opposed to this understanding of spirituality. Notions of indigenous spirituality are more closely integrated into the culture and ways of living in tribal communities, and thus necessitate a more holistic or comprehensive research approach (Fleming and Ledogar 2008). These definitions of spirituality are particularly salient within the context of social work, particularly in India and other similar nations, where spirituality and religion together form an essential aspect of cultural life. Belcher and Mellinger (2016) argued that spirituality often assists people to make sense of 
regular issues and/or life, and fortifies the interconnectedness of people and the broader community. Spirituality is deeply embedded in tribal human life, and is therefore inseparable from the context of community development and engagement initiatives in such a context.

\section{Methods}

\subsection{Study Design and Participants}

A qualitative research design involves the "logic that links data to be collected (and the conclusions to be drawn) to the initial questions of the study" (Yin 2009, p. 24). In this study, the qualitative aspects emphasized definition, experience and comprehension, which gave the researcher the opportunity to interact with individuals or groups whose experiences the researcher wanted to understand. According to Mohajan (2018), qualitative research can provide a deeper understanding of the social phenomenon, which in this case involved a greater depth of understanding of tribal spirituality in India, their spiritual practices, and the healing methodologies that they used when in crisis. Two samples were used in this study, namely students $(n=23)$ together with academics $(n=6)$ from the Social Work Department at University of Mumbai. The sample participants were seen as rich sources of data as they had spent two years immersed in the surroundings of the tribal community as part of community-based engaged teaching and learning. These participants were selected as they had conducted field work among the tribes in Maharashtra as part of their practicum, which enabled them to gain detailed first-hand knowledge and understanding of the traditions, beliefs and value systems of the aforementioned tribes. This enabled the researchers to secure rich valuable information with regards to the aim of the study.

\subsection{Data Collection}

The data was collected within the tribal community itself. The researchers undertook two field visits and spent three days during both trips interacting with the local tribal community. The interviews and focus group discussion were conducted in venues within the community surroundings. A non-probability sampling strategy, specifically purposive sampling, was used to recruit the participants for this study. Purposeful sampling is widely used in qualitative research for the identification and selection of information-rich cases related to the phenomenon of interest (Palinkas et al. 2015). As such, data was collected from students enrolled for the two-year Master's Degree Program and academics involved in the community engagement initiative of this study. The interviews and focus group discussion were conducted by the researchers during the month of November 2018. The dates for the field trips and data collection were arranged by the Head of the Department. Interviews were held with academics and there were three focus group discussions with the students. The gathered data was analyzed collectively. An interview guide was used for both the interviews and focus group discussions.

\subsection{Ethical Considerations}

The study obtained full ethical clearance from The Institutional Research Ethics committee of Durban University of Technology in July 2018. Approval was also received from Mumbai University in March 2018.The ethics number for this study was 53/18 FREC. Participants were informed that participation in the study was voluntary and that all information including identifying details would be kept confidential. Data was securely stored. Written consent was secured from all participants before proceeding with data collection.

\subsection{Data Analysis}

Thematic analysis was used to analyze the data in this study. This has been described as "a foundational method for qualitative analysis" (Braun and Clarke 2006, p. 78). It has the potential to yield a detailed, abundant and complex description of data (Braun and Clarke 2006). The following six 
steps outlined by Braun and Clarke (2006) were used to generate the themes and sub-themes that were derived for this study: (1) familiarization with the data, (2) generation of codes, (3) identification of themes from the codes, (4) revision of themes, (5) naming of themes, and (6) publication of reports. To achieve these steps, the researchers transcribed the recorded responses. Subsequent detailed associations and themes were identified within the collated transcripts. These coalesced into the themes and sub themes that reflect the major findings embedded in the data.

\section{Findings and Discussion}

The following section presents the findings and discussion. The data has been grouped into three main themes and eight sub-themes. The main themes included the characteristics of tribal communities, tribal spirituality and healing methodologies. The sub-themes comprised indigenous life, socially excluded communities, family connectedness, nature worship, indigenous spirituality, and prayers and rituals.

\section{Theme 1: Characteristics of Tribal Communities}

The first theme that emerged from the data reflected the characteristics of tribal communities. These were described as indigenous people who lived as a socially excluded community in the deep forest areas of India. They were also characterized as having a deeply connected family life. The participants described them as follows:

1. Indigenous people

(Participant 1): "The indigenous people who have actually owned that land".

(Participant 2): "It is the real citizen of that land".

(Participant 3): "They have a long history of culture".

(Participant 4): "They have the different, own culture".

2. Forest life

(Participant 1): "They are totally dependent on the forests".

(Participant2): "They live in the forest they think that the forest is the whole of their Mother Earth ... Mother nature ... gift of mother nature. They are living in one community, they own the land, they have communism ... no division of land".

As evidenced in the aforementioned excerpts, participants described the tribals as being indigenous people, or the "real citizens "of their land. This land was described as an indivisible space, as the tribals believe that it belongs to all of them within a context of reciprocity, connectedness to each other and the Earth. Hence there is a deep sense of communal living and collective identity amongst the tribals.

More importantly, they discovered that they have a long history of culture that is uniquely or distinctively their own. This uniqueness in their way of life seems to stem from the fact that they view the forest within which they live as the entire Mother Earth, which has been divinely gifted to them. Their distinctive cultural framework differs from mainstream India wherein spirituality is rooted in the Hindu paradigm. Writers such as Shivamurthy et al. (2017) and Reddy et al. (2017) concurred by describing the tribal population in India as autochthonous to the land. They tend to reside in geographical isolation, mainly in forest areas, which do not commonly coincide with mainstream society (Ramya et al. 2017; Purshottam and Dhingra 2017; Purkayastha 2016; Bhirud 2014; Shrivastava et al. 2013; Shama and Roy 2016; Reddy et al. 2017). Many of these tribes exhibit collective ownership of the land and forest resources, which facilitates an egalitarian and broadly unstructured social set-up, and also results in a reinforced sense of solidarity.

As evidenced in the data, the indigenous people's worldview of societal and cosmological relationships includes a deep understanding of respect for self, other people, and all of nature, especially the land and water. According to Vontress (2005), this philosophy is the pivotal element of 
sustainability and balanced harmonious living, which is embedded in a spiritual relationship to the land. It is through this that indigenous people such as the tribals can support each other with sacred medicines, ceremonies, and the use of other indigenous methods of traditional healing.

Moreover, as is evident in the excerpts, they survive off the land they inhabit, which is handed down from generation to generation. They remain connected not only to their natural land space but believe that there is a Spirit that is present there. These notions can be seen in the excerpts above, which reflect that they live together, as well as the unity surrounding their hamlet structure, their dependence and reverence for the forest, and their sense of deep community connectedness.

\section{Socially excluded community}

(Participant 12): "We all know that this tribes are the poorest people in the country".

(Participant 13): "Tribal communities don't have lots of resources. No basic resources".

(Participant 15): "One way of defining them is under the Indian constitution there is ... people have been defined according to their caste within that there are a group of people who are being called scheduled in the tribes who have been demarcated officially as scheduled tribes".

(Participant 10): "If you look at the human development index, tribals are the most vulnerable". (Participant 8): "When you say tribal community, it is always the area where exclusively the tribals are staying, they are on hill tops, inaccessible area and away from the main village".

(Participant 6): "In this context this is the village you have to walk a little down, some kilometres and then we reach their hamlets, there are small hamlets of each tribal community and they are not even aware of what happens".

(Participant 17): “There are houses and they don't have any locks or any doors or anything. So they're just free in that way, so they are united, they trust each other in a way that we cannot trust each other".

(Participant 23): "They are considered to be very primitive tribals who ... they have the basic things to clothe themselves but they are marginalised in terms of food, health".

4. Family connectedness

(Participant 1): "If you go there and look at the surroundings and the way the houses are situated, infrastructure in tribal village perspective, it is that only conveys that these people are united". (Participant 2): "There is a huge emphasis on family wellbeing amongst them".

(Participant 3): "Family preservation".

(Participant 4): "They stay together".

As reflected in the data, tribal communities live in deep forest areas and are regarded within the Indian constitution as "scheduled tribes". Participants described them as being amongst the poorest or most "vulnerable" in India. Their primitive way of life is evidenced in the fact that their homes are located deep in the forest, away from civilization, unaware of "what happens" in mainstream society. Their isolation from the surrounding villages is evident in that the clustering of hamlets within which they reside is "inaccessible" to others. Most important, however, is the deep sense of trust that exists amongst them, as they live together in harmony, without concern for security issues.

As described in the data, the forests have been home to these tribal communities for several generations, which makes the forest the core of the tribal economy (Ramya et al. 2017; Marchang 2018). One interesting aspect is the shared or equal workload among both males and females in the village, specifically in farming and agriculture (Panwar et al. 2014). This equality of status results in mixed or combined living arrangements for both males and females among extended families. Thus, as reflected in the data, they build homes in a concentric fashion, such that extended families may all reside in one specific area. As such, the tribal individuals possess a keen sense of affiliation with their immediate family, along with the wider community (Kapur 2018). 
The participants also described the tribals as a socially excluded community. Writers have in fact drawn attention to the oppression, subjugation, exclusion and exploitation of the tribes in India (Bodhi 2011; Ramaiah 2011). This may be attributed to the fact that they were considered as backward, isolated and in need of assimilation into mainstream society (Rao 2016). Their lifestyles consist mainly of subsistence farming and hunting (Purkayastha 2016). Communal living, as evidenced in the data, represents the collective consciousness reality by which tribals identify with each other. A consequence of these factors, which ironically influences them, is that the tribal community experiences severe shortages of resources, such as access to proper sanitation and adequate infrastructure.

Their traditionally accepted lifestyles have been predominantly self-sustaining, and display multiple divergences from mainstream culture (Ramya et al. 2017; Pati and Dash 2002). The longevity of the social and cultural life of tribals can be attributed to factors such as an enhanced degree of solidarity, greater respect for their own traditions and customs, an emphasis on meanings related to social actions, a devaluated significance of money, and an enhanced sense of camaraderie which is prevalent amongst the community members (Sehgal et al. 2018). The data reflects these notions and suggests that tribal communities appear to embrace their own unique spirituality. This spirituality is heavily influenced by nature and the respect for others within their ecosystem. What also appeared to be important was the strong relationship between families. Despite their poor living conditions, and the fact that their socially accepted concepts and traditions are divergent from mainstream society, this does not affect the cohesiveness and support that characterize tribal life. Aspects related to tribal spirituality are presented under the following theme.

\section{Theme 2: Tribal Spirituality}

Tribal spirituality emerged as the second crucial theme in the data. The sub-themes that were intertwined with this theme included nature worship, indigenous tribal spirituality, and prayers and rituals. The participant responses are reflected in the excerpts below:

1. Nature worship

(Participant 1): "They really revere nature as their God".

(Participant 5): "They are the worshipers of nature".

(Participant 2): "They believe in nature. It is called animism. So for them tree is to be worship".

(Participant 3): "An entire Hill is considered to be their God".

(Participant 4): “These tribal believe in nature worship they believe that the God of Green, Hira Dev that's what they call him. That's their God, that basically the nature, the trees, the forest, that provide them with the basic amenities that they want. That is their God".

"Katkarwadi, so they have this particular song based on their worship and their belief on the Green God, so they practice these particular beliefs in the folk dances, folk songs, folklore's so that's how we know that this is their base of belief, that this is the God that they believe in, they don't believe in worshiping idols and everything they just believe in practicing worship to the God". "They take nature as their God, private provider ... because preservation of the forest and nature is important for the future generation of them. So they have been pushing themselves to preserve, to plant more and more trees".

(Participant 5): "There is what you call totemism that exist there".

"They always pray to the nature as I know tribal communities they pray to the trees, they pray to animals, they have also some like if they constructed a well, they pray to that well also because that well gives them water, so they pray to the water also ... these are their spiritual consensus". (Participant 6): "Even they worship animals such as tiger".

"They made a certain point in the forest where they have put a stone on the name of a tiger, on the occasions of Diwali the festival of India or their festival, they have certain festivals so 
they provide, they keep a food over there as an offering to the God or the tiger, so that's how they practice".

As reflected in the data, tribals have a special respect for nature and a strong sense of community. There appears to be a deep interconnectedness between themselves and elements of the earth and the universe, be it animate or inanimate, whereby the people, landforms, trees, plants, water and celestial beings are in synergy with each other. As indicated, they revere nature as God, and refer to this God as the God of Green, who through the trees and the forest is able to sustain them. Their way of worshipping a Supreme God is through religious beliefs and practices that involve the worship of nature, animism and totemism. Prayer is undertaken to the trees, animals and sources of water. They also make offerings of food to totems as part of their spirituality.

These characteristics of tribal spirituality are mirrored in the literature as well (Tripathi 2016; Chatterjee and Sharma 2018; Kapur 2018; Pandikattu 2017). Writers have elaborated that their reverence for nature is embedded in their profound faith that deities and supernatural powers reside within natural phenomena, such as forests, mountains and aquatic bodies such as rivers, ponds or streams (Chatterjee and Sharma 2018). In several rural areas of India, many plants and animals are believed to be pious and sacred, which aids in distributing cultural values among the tribal communities (Kandari et al. 2014). By incorporating the practice of nature worship and demonstrating respect and confidence in the mystical nature of terrestrial phenomena, tribals promote and encourage happiness, whilst simultaneously upholding the religious conviction that they can ward off evil (Chatterjee and Sharma 2018; Sehgal et al. 2018).

As such, as found in the data, they worship nature and turn their prayers towards the God of Green, "Hira Dev". A further reason for this reverence of nature is that it provides them with food as sustenance in the absence of formal livelihoods in these spaces. Whilst most of India adheres to Hinduism as their faith, and worships idols who represent the different Gods and Goddesses, the tribal community worship nature as their God. Community and connectedness with land and nature is experienced in a way that provides proper nutrition and shelter.

Both plants and animals, then, are considered as manifestations of divine energy. The data revealed that they pray to animals or totems as well. The tribal cultures are known to give greater prominence to earth-bound creatures, such as serpents, tigers, rodents, etc. (Pandikattu 2017). In essence, this can be regarded as a form of totemism, which is commonly practiced among tribal communities in India (Amirthalingam 2014). Totemism can be described as "a complex of varied ideas and ways of behaviour based on a world view drawn from nature" (Dagba et al. 2013, p. 145). Esteemed sociologist of the 20th century Emile Durkheim further classified totemism as the oldest and purest form of religion (Eswarappa and Mathew 2019). According to Durkheim, totemism integrates the community, the individual and the group, while simultaneously strengthening social life by dispersing social values and moral beliefs, thus forming the 'collective conscience', wherein all community members share a joint solidarity in spiritual belief (Barla 2019). As indicated by one of the participants, offerings are made to stones which are regarded as totems that represent tigers. Grieves (2006) wrote that spirituality is a "connectedness to the past, ancestors, and the values that they represent, for example respect for elders, a moral/ethical path" (p. 52). Thus what appears is that people, plants, trees or places are linked to the spirit of creation, as well as mutually to each other, which ... called "mutual spirit being", and this is also considered as totemism. As Grieves (2008), said the totemic relationship is predicated on the belief that people assume relationships with the species and the totemic site, or sacred site, in the landscape.

Despite these forms of worship, and partly due to population growth and increased exposure over an extended time span, tribal communities have been influenced to a certain extent by mainstream Hindu culture, which has resulted in a portmanteau of beliefs (Pandikattu 2017; Chatterjee and Sharma 2018). This is evident in the worship and acknowledgment of established Hindu deities, such as Kali Mata and Durga Mata, along with other gods and goddesses (Pandikattu 2017). Hence some tribal homes now have these idols as well. 
2. Indigenous spirituality

(Participant 1): "So as generation to generation, so we pray to the God, for our ancestors have prayed".

(Participant 2): "This tradition is coming from the ancient people, so they are not understanding why they are doing ... they just following".

"So it passes down. Continues through like oral, there's nothing written as such".

(Participant 3): "The belief, superstitious beliefs ... because these tribal people believe on superstition a lot". "They will go and worship a tree and they will light diya".

(Participant 4): "Morality play the very important role in the tribal culture ... there is a lot to learn from the tribal culture".

(Participant 5): "It's not written, it's not recorded anywhere but still people remember all songs, each and every piece of that song. Each song has a meaning. Different meanings related to the present context and the previous context considering the nature and the issues that they are facing. Every song has a specific issue".

(Participant 6): "There are songs on social issues, the community. They have their unique songs".

The data revealed that the tribal community has their own spirituality, which is unique to them as indigenous peoples. This spirituality has been passed down from ancient times, through the generations. There are no sacred texts amongst the tribals, like the Bible or Bhagavad Gita, but rather their spirituality is passed onto each generation orally. It would also appear that the spiritual values and principles that guide them are embedded in stories and songs which hold a deep meaning to them, and become sources of strength during times of difficulty. Gray et al. (2013) described indigenous peoples as those "culturally and geographically dispersed groups with diverse histories ... similarities are found in ancestral birthright in the land, a common core of collective interests concerning the human, territorial and cultural rights" (pp. 5-6). They added that indigenous peoples reside in mountains, woodlands and forests, as do the tribals in this study, and they identify themselves with their physical environments and territories, along with their affiliation to an extended family, clan, village or tribe. Moreover, each has their own unique history, worldview, culture, language, dress, food and sacred and secular ceremonies, as reflected within the excerpts that follow.

3. Prayers and rituals

(Participant 1): "They do individual prayers these people like in their family, in their homes"

(Participant 2): "Have individual prayers of such but the community makes a song in their own language which has been used".

(Participant 3): "For every problem they face and for every joyous occasion as well they have this song".

(Participant 4): “They celebrate. They have a particular dance form, they do a dance on that day. Particular dance for a particular ritual".

(Participant 5): “They use a drum".

(Participant 6): "Local instrument whatever they get ... ".

"They use sticks and beat on that and they also make noise".

As evidenced in the data, whilst the tribals undertake individual prayer at home with their families, they also engage in communal prayer. Rituals appear to be undertaken with song and dance, which have their own special meanings. Music and dance are regarded as an integral aspect of tribal life (Pati and Dash 2002; Purshottam and Dhingra 2017). Celebrations and rituals are often accompanied by dance, music, and the playing of various musical instruments (Pandikattu 2017; Chatterjee and Sharma 2018). As one participant described, drums, sticks and local instruments are used as part of celebrations. 
In fact, important characteristics and functions of traditional folklore have been conveyed for generations in the forms of oral narratives, songs and music. Personal and communal empowerment, then, appears to be derived during ritual ceremonies, which help people develop common identity and support each other as they eat, dance and rejoice together.

Some tribal culture rituals are organized in such a way that celebrations take roughly 24 hours. The night is spent in communal rhythmic movements, such as drumming, dancing, and singing, which can often lead the participants to a crowd catharsis (Pandikattu 2017).

Tribal ritual activity is often addressed to sacred beings, such as Gods or ancestors (Laungani 2005). Smart (1998) described such rituals as focused rituals, where the focus is on worship and personal communication with the Gods. According to Hay (2018), a ritual ceremony brings people and all living and non-living entities of the Universe together. Ceremony "incorporates stories, music, dance, by which the characters and events of the eternity ... are brought into the sacred space" (Grieves 2008, p. 376). Ceremonial life, as evidenced in the data, is a deep expression of tribal spirituality. The excerpts indicate that a common practice of Indian tribals throughout the year is participation in various religious events, which helps to bring about social camaraderie, communal solidarity and conformity in their society (Chatterjee and Sharma 2018).

\section{Theme 3: Healing Methodologies}

Healing methodologies was the third theme that emerged from the data. The excerpts below reflect the responses from participants.

(Participant 15): “Tribal people have rich knowledge, what we call indigenous knowledge of plants". (Participant 16): "Even there is a health problem people are not aware of, they are not aware about how to cure a disease means still they uses the old traditional Ayurvedic medicines to cure themselves. Most of them are frightened to visit a doctor".

(Participant 17): "The people who had some kind of understanding of medicine became traditional healers because the village is self-sufficient ... they don't have to rely on others".

(Participant 18): "They have their own way of healing themselves. In every place there is one person who is, has a very good understanding of the nature, take Ayurvedic medicines from the forest, make a tablet of that, herbs".

(Participant 19): "He consult with the rest of the village then so if they get sick the people go to him, is he called a Vaidya".

(Participant 20): "He don't share the formula with anyone even not with his family".

"It is indigenous knowledge that he has gained but he doesn't share that with the family or other people of the village".

(Participant 21): "We seen a person over here who cures snake bites but by doing some spiritual work like sprinkling water on that affected person, the person get healed ... so most people who have problems by snake biting they come to him and they are good now we also".

(Participant 22): "Music is part of the healing process".

Participants reported that the tribals seek the help of traditional healers when confronted with problems related to their physical health and psycho-spiritual health. It is evident that within these deep forest areas, healers serve as doctors, and are the cornerstone of tribal healing methodologies. Indigenous knowledge systems can be defined as "the sum total of the knowledge and skills which people in a particular geographic area possess, and which enables them to get the most of the natural environment" (Grenier 1998 cited in (Hoppers 2017, p.2)). Participants also reported that these healers use herbs to make medicines, as they have a deep understanding of what herbs can be used to treat various ailments. Healthcare and medicinal treatment has thus been historically treated naturally by the use of various plants and natural remedies, specifically by traditional healers in lieu of medical professionals (Kapur 2018; Mahant 2015). 
Participants described this as "Ayurvedic medicine", a process whereby healers distill medicine from certain herbs found in the forest to treat various physical and emotional conditions. In India, Ayurveda is the term used to refer to a natural system of healing which relies on the use of herbs, amongst other approaches to health and well-being (Lad 2016). As reflected in the data, those who tend to the sick use knowledge that again is passed on from elders in previous generations. As the participants said, tribal members have acquired profound knowledge, developed through a significant awareness of their local environments and detailed ecological processes that has been transmitted through the passage of time (Dwivedi 2015; Mahant 2015; Aadhan and Anand 2018). Thus, they possess distinctive knowledge on the usage of assorted plant parts in the curing of ailments, and have evolved into experts in using different formulations containing plant parts to cure ailments as a type of primary health care. This is a component of their cultural practices, and founds their ability to sustain health and prevent diseases among them (Dwivedi 2015; Mahant 2015; Aadhan and Anand 2018). Unfortunately, the knowledge and understanding of medicinal properties and remedies is still mostly in the hands of the healers, who by and large are elderly members of the community, potentially exacerbating the risk of such practices not continuing into the future (Mahant 2015; Aziz et al. 2018). However, what appears is that it is passed down through the generations to others who are revered as healers in the community.

\section{Discussion and Conclusions}

This study found that the tribal way of living, knowing and being in the world is embedded within both the simplicity and the complexity of their psycho-spiritual-socio-ecological cosmological worldview. The tribal community was found to be indigenous to its area for many generations, and has as such developed its own spiritual worldview. This unique spirituality is characterized by a reverence for nature and an emphasis on family bonds, and a celebratory culture and rituals that are deeply ingrained in their psychological makeup.

Most significantly, the study uncovered a variety of different aspects regarding the cultural and spiritual philosophies within the tribal community. Nature and natural phenomena are prioritized as their religion. This is expressed as animism, which prioritizes plants and animals as symbols of divinity. The term animism is the belief that a soul or spirit exists in all objects, even inanimate ones (Yoneyama 2017; Nosonovsky 2018). Nosonovsky (2018) added that animists perceive all manner of entities, both sentient and non-sentient, as being animated and alive. Levy (1967) declared that because the soul is considered eternal and divine, it may pass not only between humans but also into other plants animals, inanimate objects and the like. As such, in the animist view of the world, humans are a link in the cosmic chain of events that summons lower orders (minerals, plants and animals) to join higher ones (spirits, ancestors and gods) (Vontress 2005).

For the students and academics involved in the study, their immersion in the tribal community has enhanced their knowledge of the community and their ability to relate to them. The community engagement initiative strengthened notions that diversity can be emancipating, and that information generation can shift from a top-down flow, from academy to community, to a mutual and reciprocal association whereby community spaces may become learning spaces, with community members as teachers of indigenous knowledge. Indigenous spirituality is rich with potential, not in terms of specific answers or strategies, but rather with connections and possibilities to be explored further by teachers, administrators and educators (Ritskes 2011). Students and academics alike were able to understand tribal spirituality more richly through their immersion in this community, which enabled them to engage in community development initiatives more easily.

Tribal social work in India seeks to derive its theories and methods from the histories and cultures of indigenous peoples, and moves away from the inappropriateness of western theories in an effort to mold its own ideas about equality and inequality, inclusion and exclusion, social justice and injustice, and rights and fairness. As such, an understanding of tribal spirituality is crucial to working successfully with such communities where social work intervention is most needed. This is in keeping with the indigenization of social work in India, which requires the development of knowledge that 
takes into account the socio-political and economic context of people's lives, as well as ethnocentric factors such as caste, tribe, religion and culture. These factors influence the development of poor and marginalized sectors of the population. Decolonized social work cannot remain at a disjuncture from religion, as social workers who work with individuals, groups and communities must be respectful of related religious, caste, ethnic and cultural differences. This paper reflects the rich learning potential that emerged through close and intimate engagement with the tribal community in India.

Author Contributions: Data was collected and analyzed by S.R. and R.B. Both authors contributed equally to this paper. R.B. approved the final manuscript. All authors have read and agreed to the published version of the manuscript.

Funding: This research received no external funding.

Acknowledgments: The authors declare that they have no financial funding or personal relationship(s), which may have inappropriately influenced them in writing this article.

Conflicts of Interest: The authors declare no conflict of interest.

\section{References}

Aadhan, Kamatchi, and Subramaniam Parvathi Anand. 2018. Wild Ethno Pharmacognosy Plants Utilize for the Treatment of Jaundice by Paliyar Tribe in Sathuragiri Hills, a Part of Western Ghats, Tamil Nadu, India. International Journal of Pharma Res Health Science 6: 210.

Amirthalingam, Murugesan. 2014. Significance of Totemism among the Tribes of India. ECO NEWS 19: 22. Available online: https://www.researchgate.net/profile/Amirthalingam_Murugesan/publication/312176533_ Significance_of_Totemism_among_the_Tribes_of_India/links/5874d54108ae8fce4927e24a/Significance-ofTotemism-among-the-Tribes-of-India.pdf (accessed on 10 January 2019).

Andrabi, Azad Ahmad. 2018. A Study of Academic Achievement among Tribal and Non-Tribal Adolescents of Kashmir. Available online: http://www.academia.edu/download/42125070/19._andrabi.pdf (accessed on 9 July 2020).

Aziz, Muhammad Abdul, Muhammad Adnan, Amir Hasan Khan, Abdelaaty Abdelaziz Shahat, Mansour S. Al-Said, and Riaz Ullah. 2018. Traditional uses of medicinal plants practiced by the indigenous communities at Mohmand Agency, FATA, Pakistan. Journal of Ethnobiology and Ethnomedicine 14: 2. Available online: https://link.springer.com/article/10.1186/s13002-017-0204-5 (accessed on 5 February 2019). [CrossRef] [PubMed]

Barla, Amrit. 2019. Contextualizing Religion and Festival in Transition: With Special Reference to Oraon Indigenous Tribe in India. Available online: https://scholar.google.com/scholar?hl=en\&as_sdt=0\%2C5\& $\mathrm{q}=$ amrit+barla+contextuaizing +religgion + and + festival + in + transition\&btnG $=($ accessed on 16 September 2020).

Belcher, John R., and Marcela Sarmiento Mellinger. 2016. Integrating spirituality with practice and social justice: The challenge for social work. Journal of Religion \& Spirituality in Social Work: Social Thought 35: 377-94. Available online: https://www.tandfonline.com/doi/abs/10.1080/15426432.2016.1229645 (accessed on 12 January 2019).

Bhagwan, Raisuyah. 2017. Towards a conceptual understanding of community engagement in higher education in South Africa. Perspectives in Education 35: 171-85. [CrossRef]

Bhatla, Sunita. 2017. Educational Status of Socially Disadvantaged Group in India. Scholarly Research Journal for Interdisciplinary Studies (SRJIS) 4: 6282-93.

Bhirud, Vibha. 2014. The Concept of Tribe and Their Major Problems in India (26 September 2014). MS Gore Policy Evaluation Group. Available online: https://papers.ssrn.com/sol3/papers.cfm?abstract_id=2820218 (accessed on 5 February 2019).

Bodhi, S. Ranee. 2011. Professional Social Work Education in India: A Critical View from the Periphery (Discussion Note). The Indian Journal of Social Work 72: 289-300.

Braun, Virginia, and Victoria Clarke. 2006. Using thematic analysis in psychology. Qualitative Research in Psychology 3: 77-101. Available online: https://www.tandfonline.com/doi/abs/10.1191/1478088706QP063OA (accessed on 10 January 2019). [CrossRef] 
Campbell, Matthew, and Michael J. Christie. 2009. Researching a University's engagement with the Indigenous communities it serves. Learning Communities: International Journal of Learning in Social Contexts 1: 2-22. Available online: http://espace.cdu.edu.au/view/cdu:24307/Campbell_24307.pdf (accessed on 9 January 2019).

Canda, Edward R., Leola Dyrud Furman, and Hwi-Ja Canda. 2010. Spiritual Diversity in Social Work Practice: The Heart of Helping. Oxford: USA Oxford University Press.

Chatterjee, Subhasish, and Rahul Sharma. 2018. Belief of tribal's in supernatural power and its relation with religious life (with special reference to Indian tribal society). International Journal of Research and Analytical Reviews 5: 48-55.

Chaube, Nandita. 2015. Spirituality and Human Psyche. India: Partridge Publishing.

Clark, Janet. 2000. Beyond Empathy: An Ethnographic Approach to Cross-Cultural Social Work Practice. Unpublished Manuscript. Toronto: Faculty of Social Work, University of Toronto.

Dagba, Benjamin I., Leoskali N. Sambe, and Simon A. Shomkegh. 2013. Totemic beliefs and biodiversity conservation among the Tiv People of Benue State, Nigeria. Journal of Natural Sciences Research 3: 145-49. Available online: https://oer.uam.edu.ng/read/totemic-beliefs-and-biodiversity-conservation-among-the-tivpeople-of-benue-state-nigeria-1/file.pdf (accessed on 5 January 2019).

Das, Subal, and Kaushik Bose. 2015. Adult tribal malnutrition in India: An anthropometric and socio-demographic review. Anthropological Review 78: 47-65. Available online: https://content.sciendo.com/view/journals/anre/7 8/1/article-p47.xml (accessed on 5 January 2019). [CrossRef]

Dombo, Eileen A., and Megan Flood. 2015. Spirituality in Fertility Counseling. In Fertility Counseling: Clinical Guide and Case Studies. Edited by Sharon N. Covington. Cambridge: Cambridge University Press, pp. 74-84.

Drury, Connie Francis. 2016. Discomfort in Addressing Spiritual Needs: A Hospital-Wide Exploration into the Hole in Holistic Care. Ph.D. dissertation, University of Missouri, Kansas City, MO, USA. Available online: https://scholar.google.com/scholar?hl=en\&as_sdt=0\%2C5\&q=Drury\%2C+C.F.\%2C+2016.+Discomfort+ in + Addressing + Spiritual + Needs $\% 3 \mathrm{~A}+\mathrm{A}+$ Hospital-Wide+Exploration + into + the + Hole + in + Holistic $+\mathrm{C}$ are+\%28Doctoral+dissertation $\% 2 \mathrm{C}+$ University+of+Missouri--Kansas+City\%29.\&btnG= (accessed on 10 September 2020).

Dwivedi, Jyoti. 2015. The dependence of Andaman and Nicobar island tribal communities on herbal remedies. Journal of Environmental Science, Toxicology and Food Technology 9: 45-53.

Eswarappa, Kasi, and Gladis S. Mathew. 2019. Animatism and Religion. Available online: https://scholar.google.c $\mathrm{om} /$ scholar?hl=en\&as_sdt=0\%2C5\&q=Animatism\&btnG $=$ (accessed on 16 September 2020).

Fleming, John, and Robert J. Ledogar. 2008. Resilience and Indigenous Spirituality: A Literature Review. Pimatisiwin 6: 47. Available online: https://www.ncbi.nlm.nih.gov/pmc/articles/pmc2956755/ (accessed on 1 July 2020). [PubMed]

Gray, Mel. 2002. Developmental Social Work: A Strengths' Praxis for Social Development. Social Development Issues 24: 4-14. Available online: https://scholar.google.com/scholar?hl=en\&as_sdt=0\%2C5\&q=+\%22Develo pmental+Social+Work\%3A+A+Strengths\%27+Praxis+for+Social+Development.\%22+Social+Developme $\mathrm{nt}+\& \mathrm{btnG}=$ (accessed on 16 September 2020).

Gray, Mel, John Coates, and Michael Yellow Bird, eds. 2010. Indigenous Social Work around the World: Towards Culturally Relevant Education and Practice. Farnham: Ashgate Publishing, Ltd.

Gray, Mel, John Coates, Michael Yellow Bird, and Tiani Hetherington. 2013. Introduction: Scoping the Terrain of Decolonization. Burlington: Ashgate Publishing, Ltd., Available online: https://www.researchgate.net/publica tion/286857582_Introduction_Scoping_the_terrain_of_decolonization.pdf (accessed on 25 July 2020).

Grenier, Louise. 1998. Working with Indigenous Knowledge: A guide for Researchers. Ottawa: IDRC, Available online: https://scholar.google.com/scholar?hl=en\&as_sdt=0\%2C5\&q=Grenier\%2C+L.+1998.+Working+with+ind igenous+knowledge\%3A+A+guide+for+researchers.+Ottawa\%3AInternational+Development+Researc $\mathrm{h}+$ Centr\&btnG $=($ accessed on 16 July 2020).

Grieves, Vicki. 2006. Indigenous Wellbeing: A Framework for Governments' Cultural Heritage Activities. Sydney: NSW Department of Environment and Conservation.

Grieves, Vicki. 2008. Aboriginal Spirituality: A Baseline for Indigenous Knowledge Development in Australia. The Canadian Journal of Native Studies 28: 363-98. Available online: http://www3.brandonu.ca/cjns/28.2/07Gri eves.pdf (accessed on 29 July 2020). 
Hall, Martin. 2010. Community engagement in South African higher education. In Community Engagement in South African Higher Education. Edited by South African Council on Higher Education. Pretoria: CHE, Kagisano No. 6. pp. 1-52. Available online: http://ahero.uwc.ac.za/index.php/http://us-cdn.creamermedia.co.za?modu le $=$ cshe\&action $=$ downloadfile \&fileid $=18409092513316751038744$ (accessed on 28 July 2020).

Hay, Anette. 2018. Second home tourism: Social and economic change in developing countries like South Africa. In Tourism in Transitions. Cham: Springer, pp. 97-115.

Hoppers, Catherine A. Odora. 2017. Culture, Indigenous Knowledge and Development. Braamfontein: Centre for Education Policy Development, Available online: http://ahero.uwc.ac.za/index.php/?module=cshe\&action= downloadfile\&fileid=23994111647093965583\#: \{\}:text=Within\%20this\%20template\%2C\%20the\%20notion, environment\%20(Grenier\%20\%2C\%201998) (accessed on 25 July 2020).

Jakovljevic, Miro. 2017. Psychiatry and Religion: Opponents or Callaborators? Psychiatria Danubina 29: 82-88.

James, Lovely Awomi. 2015. Indigenous spirituality: Insights for a life-affirming and life-sustaining economy of life. The Ecumenical Review 67: 203-8. Available online: https://go.gale.com/ps/i.do?id=GALE\%7CA426 765932\&sid=googleScholar\&v=2.1\&it $=\mathrm{r} \&$ linkaccess $=$ abs\&issn $=00130796 \& \mathrm{p}=\mathrm{AONE} \& \mathrm{sw}=\mathrm{w}($ accessed on 1 July 2020). [CrossRef]

Kandari, Laxman Singh, Vinod Kumar Bisht, Meenakshi Bhardwaj, and Ashok Kumar Thakur. 2014. Conservation and management of sacred groves, myths and beliefs of tribal communities: A case study from north-India. Environmental Systems Research 3: 16. Available online: https://ink.springer.com/article/10.1186/s40068-014-0 016-8 (accessed on 5 February 2019). [CrossRef]

Kapur, Radhika. 2018. Indian Society-Urban, Rural and Tribal. New Delhi: University of Delhi.

Kechutzar, Sashikaba. 2008. Omen, Divination and Dream (Tatakruts€u, Antokdangba/Ams€u and Pongmang): Medium for Divine Revelation. In Garnering Tribal Resources for Doing Tribal Christian Theology. Edited by Razouselie Lasetso. Tribal Study Series No. 16. Jorhat: ETC Programme Coordination.

Kincheloe, Joe L. 2011. Critical ontology and indigenous ways of being: Forging a postcolonial curriculum. In Key Works in Critical Pedagogy. Leiden: Brill Sense, pp. 333-49.

Lad, Vasant. 2016. Ayurveda-A Brief Introduction and Guide. Available online: https://www.ayurveda.com/pdf /intro_ayurveda.pdf (accessed on 11 September 2019).

Laungani, Pittu. 2005. Hindu spirituality and healing practices. Multicultural Aspects of Counseling Series 22: 138.

Levy, Donald. 1967. Macrocosm and microcosm. In The Encyclopedia of Philosophy. Edited by P. Edwards. New York: Macmillan, Vol. 5, pp. 121-25. Available online: https://scholar.google.com/scholar?hl=en\&as_sdt=0\% 2C5\&q=\%28levy+1967\%29+.+macrocosm + and + microcosm. + pdf\&btnG $=($ accessed on 15 September 2019).

Mahant, Sushila D. 2015. Indigenous traditional healing care: Belief \& practices among Tribals of South Bastar in Chhattisgarh. IOSR Journal of Humanities and Social Scienceis 20: 49-54. Available online: https://www.academia.edu/download/47611180/H020114954.pdf (accessed on 1 February 2019).

Marchang, Reimeingam. 2018. Land, Agriculture and Livelihood of Scheduled Tribes in North-East India. Journal of Land and Rural Studies 6: 67-84. Available online: https://journals.sagepub.com/doi/abs/10.1177/232102491 7732905 (accessed on 4 February 2019). [CrossRef]

McGoldrick, Monica, and Kenneth V. Hardy, eds. 2019. Re-Visioning Family Therapy. New York: Guilford Publications.

Mizrahi, Terry, Esperanza Martell, Kate Cavanagh, and Allison Weingarten. 2016. In A transformative healing educational model for teaching community organizing. In Holistic Engagement: Transformative Social Work Education in the 21st Century. Edited by Loretta Pyles and Gwendolyn J. Adam. New York: Oxford University Press, pp. 57-82.

Mohajan, Haradhan Kumar. 2018. Qualitative research methodology in social sciences and related subjects. Journal of Economic Development, Environment and People 7: 23-48. [CrossRef]

Nimmagadda, Jayashree, and Diane R. Martell. 2010. Home-made social work: The two-way transfer of social work practice knowledge between India and the USA. In Indigenous Social Work around the World: Towards Culturally Relevant Education and Practice. Edited by Gray Mel, John Coates, Michael Yellow Bird and Tiani Hetherington. Farnham: Ashgate, pp. 141-52.

Nosonovsky, Michael. 2018. Cultural implications of biomimetics: Changing the perception of living and non-living. MOJ Applied Bionics and Biomechanics 2: 230-36. Available online: https://scholar.google .com/scholar?hl=en\&as_sdt=0\%2C5\&q=Nosonovsky+2018+cultural+implications\&btnG $=($ accessed on 12 September 2020). [CrossRef] 
O'Donahoo, Francis J., and Kirstin E. Ross. 2015. Principles relevant to health research among Indigenous communities. International Journal of Environmental Research and Public Health 12: 5304-9. Available online: https://www.mdpi.com/1660-4601/12/5/5304 (accessed on 10 February 2019).

Palinkas, Lawrence A., Sarah M. Horwitz, Carla A. Green, Jennifer P. Wisdom, Naihua Duan, and Kimberly Hoagwood. 2015. Purposeful sampling for qualitative data collection and analysis in mixed method implementation research. Administration and Policy in Mental Health and Mental Health Services Research 42: 533-44. Available online: https://link.springer.com/article/10.1007/s10488-013-0528-y (accessed on 10 January 2019).

Pandikattu, Kuruvilla. 2017. Unit-2. Dalit Folklore and Cultural Expressions. New Delhi: IGNOU.

Panwar, Manju, Deepali Mathur, Gian Chand, Manju Dkhaka, R. R. Singh, and David P. Moxley. 2014. Action learning in the Indian village as an alternative to the traditional field practicum in the foundation year of the MSW. Social Work Education 33: 984-97. Available online: https://www.tandfonline.com/doi/abs/10.1080/0261 5479.2014.921285 (accessed on 1 March 2019). [CrossRef]

Pati, Rabindra Nath, and Jagannatha Dash. 2002. Tribal and Indigenous People of INDIA: Problems and Prospects. New Delhi: APH Publishing.

Prasad, Devi B., and Vijayaslakshmi. 1997. Field instruction for social work education in India: Some issues. Indian Journal of Social Work 58: 65-77. Available online: https://scholar.google.com/scholar?hl=en\&as _sdt=0\%2C5\&q=1.\%09Devi+Prasad \%2C+B+and+Vijayalakshmi\%2C+B.+\%281997\%29.+Field+instruction +in+Social+Work+education+in+India\%3A+Some+issues\%2C+Indian+Journal+of+Social+work\%2C+58+ $\% 281 \% 29 \% 3 \mathrm{~A}+65-77 . \& b \operatorname{tnG}=$ (accessed on 15 September 2020).

Purkayastha, Nabarun. 2016. Concept of Indian Tribes: An Overview. International Journal of Advanced Research in Management and Social Sciences 5: 1-9. Available online: http://www.indianjournals.com/ijor.aspx?target=ijor: ijarmss \&volume $=5 \&$ issue $=2$ \&article $=001$ (accessed on 4 February 2019).

Purshottam, and Vanita Dhingra. 2017. Understanding the Indian tribal life and their issues. International Journal of Advanced Research 5: 1588-95.

Ramaiah, Avatthi. 2011. Growing crimes against Dalits in India despite special laws: Relevance of Ambedkars demand for separate settlement. Journal of Law and Conflict Resolution 3: 151-68. Available online: https://academicjournals.org/journal/JLCR/article-abstract/2F95A1F7733 (accessed on 29 July 2020).

Ramya, H. S., Parthiban S. Gopal, Suhanya Veronica Prasad, and Leeberk Raja. 2017. Characteristics Determining the Livelihood Security of the Tribal Farmers. International Journal of Current Microbiology and Applied Sciences 6: 4462-70. [CrossRef]

Rao, Vidya. 2016. Decolonizing social work: An Indian viewpoint. In Decolonizing Social Work. Abingdon: Routledge, pp. 69-87.

Reddy, B. Venkatashiva, Yadlapalli S. Kusuma, Chandrakant S. Pandav, Anil Kumar Goswami, and Anand Krishnan. 2017. Water and sanitation hygiene practices for under-five children among households of Sugali tribe of Chittoor District, Andhra Pradesh, India. Journal of Environmental and Public Health. Available online: https://www.hindawi.com/journals/jeph/2017/7517414/abs/ (accessed on 10 January 2019).

Ritskes, Eric. 2011. Chapter Twenty-Six: Indigenous Spirituality and Decolonization: Methodology for the Classroom. Counterpoints 379: 411-21.

Sehgal, Ranjana, Silima Nanda, Bhoumick Desmukh, and Rubina Nusrat. 2018. Block-3 Tribals of Central India. Available online: http://www.egyankosh.ac.in/bitstream/123456789/50384/1/Block-3.pdf (accessed on 10 January 2019).

Shama, Ravendra K., and J. Roy. 2016. Socio-Economic and Demographic Characteristics of Three Most Backward Tribes of Madhya Pradesh. Available online: https://www.researchgate.net/profile/Ravendra_Sharma2/publi cation/309476374_Socio-economic_and_demographic_characteristics_of_three_most_backward_tribes_of _Madhya_Pradesh/links/58db42dc92851ce5e9670f67/Socio-economic-and-demographic-characteristics-of -three-most-backward-tribes-of-Madhya-Pradesh.pdf (accessed on 10 March 2020).

Shivamurthy, Y.L., H.K. Rashmi, Hassan S. Rajani, and Doddaiah Narayanappa. 2017. A Comparative Study on Sociodemographic Characteristics between Tribal and Non-Tribal Children. Pediatric Education and Research 5: 129. Available online: https://www.researchgate.net/profile/Kallenahalli_Kumar/publication/318984804_N utrient_Consumption_among_Tribal_and_Non_Tribal_Children/links/5b6bea3b299bf14c6d97070c/Nutrie nt-Consumption-among-Tribal-and-Non-Tribal-Children.pdf\#page=81 (accessed on 20 January 2020). 
Shrivastava, Saurabh Rambiharilal, Prateek Saurabh Shrivastava, and Jegadeesh Ramasamy. 2013. Implementation of public health practices in tribal populations of India: Challenges and remedies. Healthcare in Low-Resource Settings 1: e3. Available online: http://pagepressjournals.org/index.php/hls/article/view/734 (accessed on 10 January 2019). [CrossRef]

Slade, Mike. 2011. Personal Recovery and Mental Illness: A Guide for Mental Health Professionals. Cambridge: Cambridge University Press.

Smart, Ninian. 1998. The World's Religions. Cambridge: Cambridge University Press.

Tieken, Mara C. 2017. The Evolution of a Community-Engaged Scholar. Metropolitan Universities 28: 8-16. Available online: https://journals.iupui.edu/index.php/muj/article/view/21508 (accessed on 7 January 2019). [CrossRef]

Tripathi, Prakash. 2016. Tribes and forest: A critical appraisal of the tribal forest right in India. Research Journal of Social Science and Management 6: 8. Available online: https://pdfs.semanticscholar.org/6677/3e9f72c5ed26c6ed 36bad404cf744261b56f.pdf (accessed on 11 January 2019).

Vontress, Clemmont E. 2005. Animism: Foundation of Traditional Healing in Sub-Saharan Africa. Integrating Traditional Healing Practices into Counseling and Psychotherapy 22: 124.

Walsh, Froma. 2008. Spirituality, healing, and resilience. In Re-Visioning Family Therapy: Race, Culture, and Gender in Clinical Practice. Edited by McGoldrick Monica and Kenneth V. Hardy. New York: The Guilford Press, pp. 61-75.

Walsh, Joseph. 2010. Theories for Direct Social Work Practice, 2nd ed. Belmont: Wadsworth.

Wangoola, Paul. 2000. Mpambo, the African multiversity: A philosophy to rekindle the African spirit. In Indigenous Knowledges in Global Contexts: Multiple Readings of Our World. Toronto: University of Toronto Press, pp. 265-77.

Weaver, Hilary N. 2000. Culture and professional education: The experiences of Native American social workers. Journal of Social Work Education 36: 415-28. [CrossRef]

Yin, Robert K. 2009. Case study research: Design and methods 4th edition. In United States: Library of Congress Cataloguing-in-Publication Data. Thousand Oaks: Sage Publications.

Yoneyama, Shoko. 2017. Animism: A grassroots response to socioenvironmental crisis in Japan. In New Worlds from Below: Informal Life Politics and Grassroots Action in Twenty-First-Century Northeast Asia. Canberra: ANU Press, pp. 99-130.

Publisher's Note: MDPI stays neutral with regard to jurisdictional claims in published maps and institutional affiliations.

(C) 2020 by the authors. Licensee MDPI, Basel, Switzerland. This article is an open access article distributed under the terms and conditions of the Creative Commons Attribution (CC BY) license (http://creativecommons.org/licenses/by/4.0/). 